\title{
Gabinete de Arquitectura
}

Solano Benítez + Alberto Marinoni

El Paraguay no tiene acceso al mar más que por un río;

es un país de ciénagas y arcilla de un color particular. Las imágenes de estas obras ayudan a despejar la mirada y

acceder a un país de caminos externos obstruidos; un país (¿periférico?) que se encuentra en el centro del continente, $y$ en el cual se sitúan estas construcciones a medio camino entre artesanía y globalización, entre intimidad y masificación.

Paraguay's only access to the sea is via a single river; it is a land of marshes and strange-coloured clay. The images of these works help clear one's gaze to penetrate a country of roads blocked to the exterior; a-peripheral? - land in the beart of the continent, bome to these constructions that hover between handicrafts and globalization, between intimacy and mass market.

Edificio Unilever Paraguay
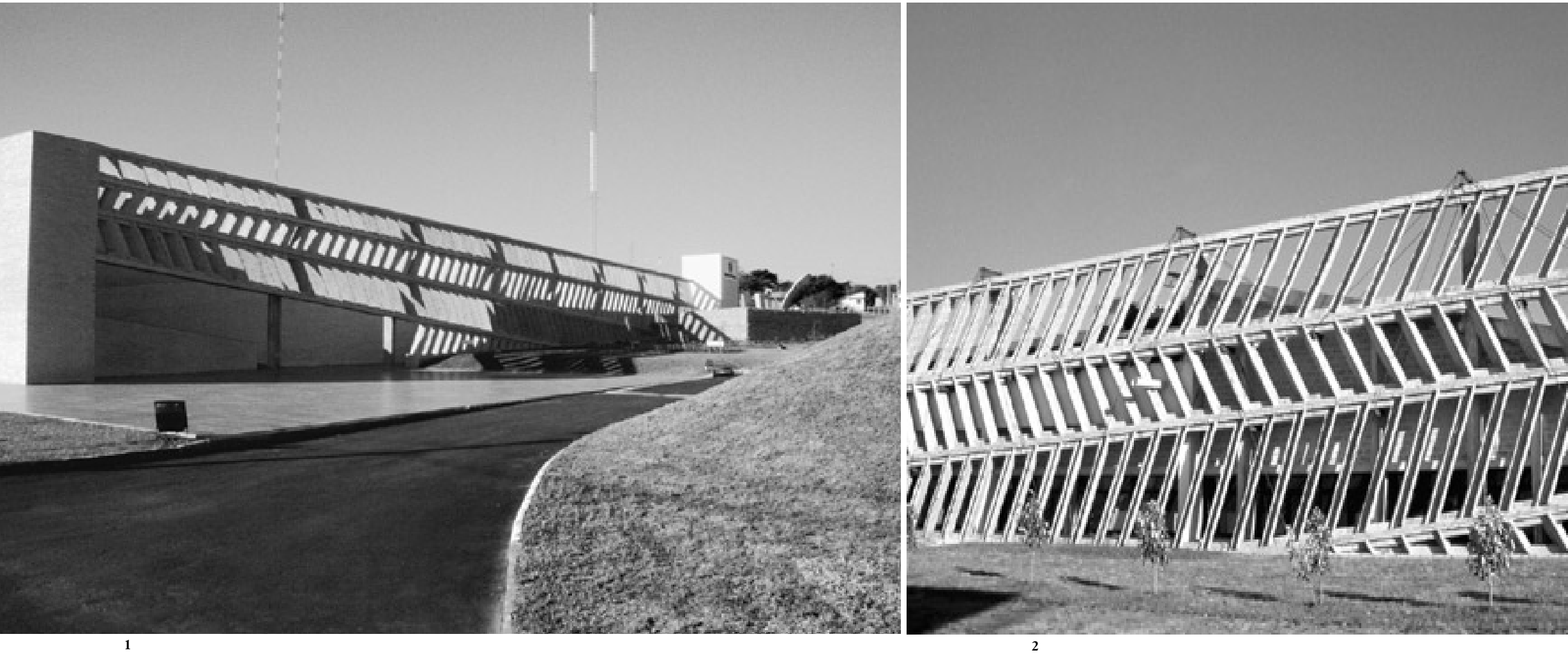

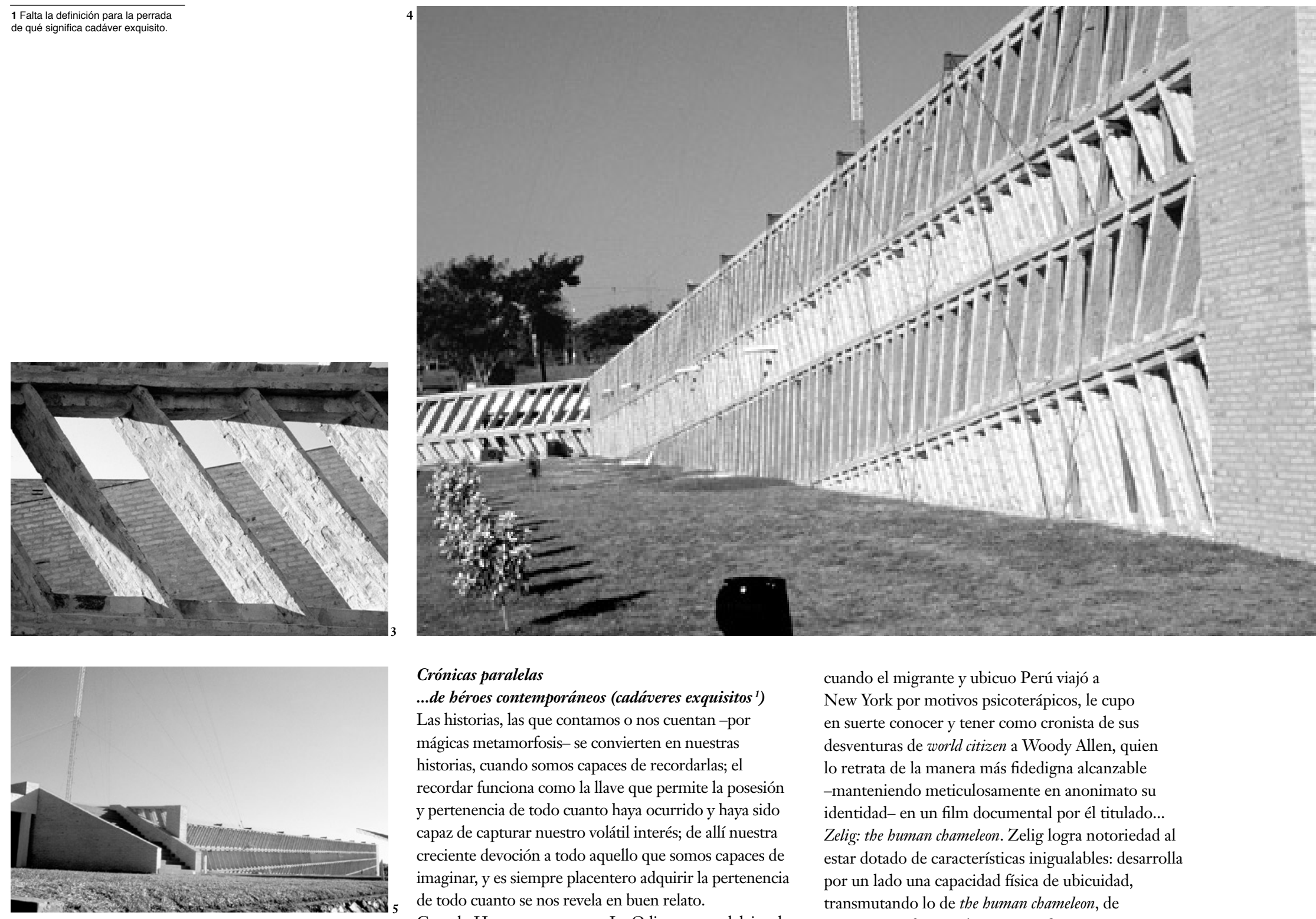

\section{Crónicas paralelas}

...de héroes contemporáneos (cadáveres exquisitos ${ }^{1}$ )

Las historias, las que contamos o nos cuentan -por mágicas metamorfosis- se convierten en nuestras historias, cuando somos capaces de recordarlas; el recordar funciona como la llave que permite la posesión y pertenencia de todo cuanto haya ocurrido y haya sido capaz de capturar nuestro volátil interés; de allí nuestra creciente devoción a todo aquello que somos capaces de imaginar, y es siempre placentero adquirir la pertenencia de todo cuanto se nos revela en buen relato.

Cuando Homero nos cuenta La Odisea, y nos deleita al introducirnos a su época, no sólo construye los caracteres de un personaje central, Ulises -Odiseo-; convierte al tiempo todos los avatares de cuanto le sucede, en la múltiple identidad de un otro protagonista, su destino -los dioses y su prodigiosa capacidad de transformarse. Lo que hace del profusamente difundido film Forrest Gump un clásico contemporáneo es una estructura similar: un personaje de simples características se confronta con las torturadas vicisitudes de un acotado tiempo, que se adaptan para permitirle atravesarlo. Creo que en la Coca Cola tenemos un correlato a nivel empresa de pensamientos similares: un único protagonista -líquido/gaseoso, en este caso-, presentado y pretendido urbi et orbi.

Simétricamente opuestos, en otras cautivantes historias en el folklore paraguayo de profunda tradición oral, habita un personaje en infinita y una historia de los relatos llamados "Perú Rimá Caso".

El Caso es una narración de ficción, con la finalidad de entretener, divertir, instruir o moralizar la vida cotidiana; su más célebre protagonista, Perú Rimá, es un personaje de difícil definición porque lo único que le caracteriza es todo.

El valor de la invención de Perú Rimá supera la capacidad de adaptación, metamorfosis mediante, de los múltiples y un personajes de Homero; Perú, al contrario, no necesita la transformación del destino para estar integrado al relato, todo relato le configura, le otorga identidad y le protagoniza. Se cree que en 1983, cuando el migrante y ubicuo Perú viajó a New York por motivos psicoterápicos, le cupo en suerte conocer y tener como cronista de sus desventuras de world citizen a Woody Allen, quien lo retrata de la manera más fidedigna alcanzable -manteniendo meticulosamente en anonimato su identidad- en un film documental por él titulado... Zelig: the buman chameleon. Zelig logra notoriedad al estar dotado de características inigualables: desarrolla por un lado una capacidad física de ubicuidad, transmutando lo de the buman chameleon, de poética metáfora en descriptiva afirmación -cuenta el documental que para el Ku Klux Klan era una triple amenaza, ya que Zelig, además de judío, podía transformarse en negro o indio-; y por otro lado alcanza la notable conciencia -en oposición a cualquiera de nosotros- que la mejor estrategia de adaptación es, siempre, la utilización del recurso del cambio, del que se hace devoto cultor.

La multinacional Lever, Unilever de Paraguay para nosotros, y con distintos otros nombres en distintos otros países, es una de las empresas representativas de estos raciocinios; diferentes mercados de consumo son pretendidos por la presentación de múltiples y variados productos, ensayando incluso en distintos lugares productos específicos, con sus alternativas y a sazón competencias; la continuidad o desaparición de cualquiera de ellos depende al tiempo de con cuánta excelencia y eficiencia se adapta el producto a su adoptativo mercado. La utilización de los estándares de la denominada imagen corporativa es una en extremo clara estrategia de presentación de empresas y productos, que se enmarcan dentro del primer grupo de nuestras comparativas asociaciones.

De cómo pretendemos -en este específico tiempo y rincón del planeta, determinado por sus propias características culturales, sociales, económicas, tecnológicas, etc.- ser capaces de cambiar para permitir la mejor adopción de una arquitectura, trata la estrategia de este particular proyecto que hemos construido. 

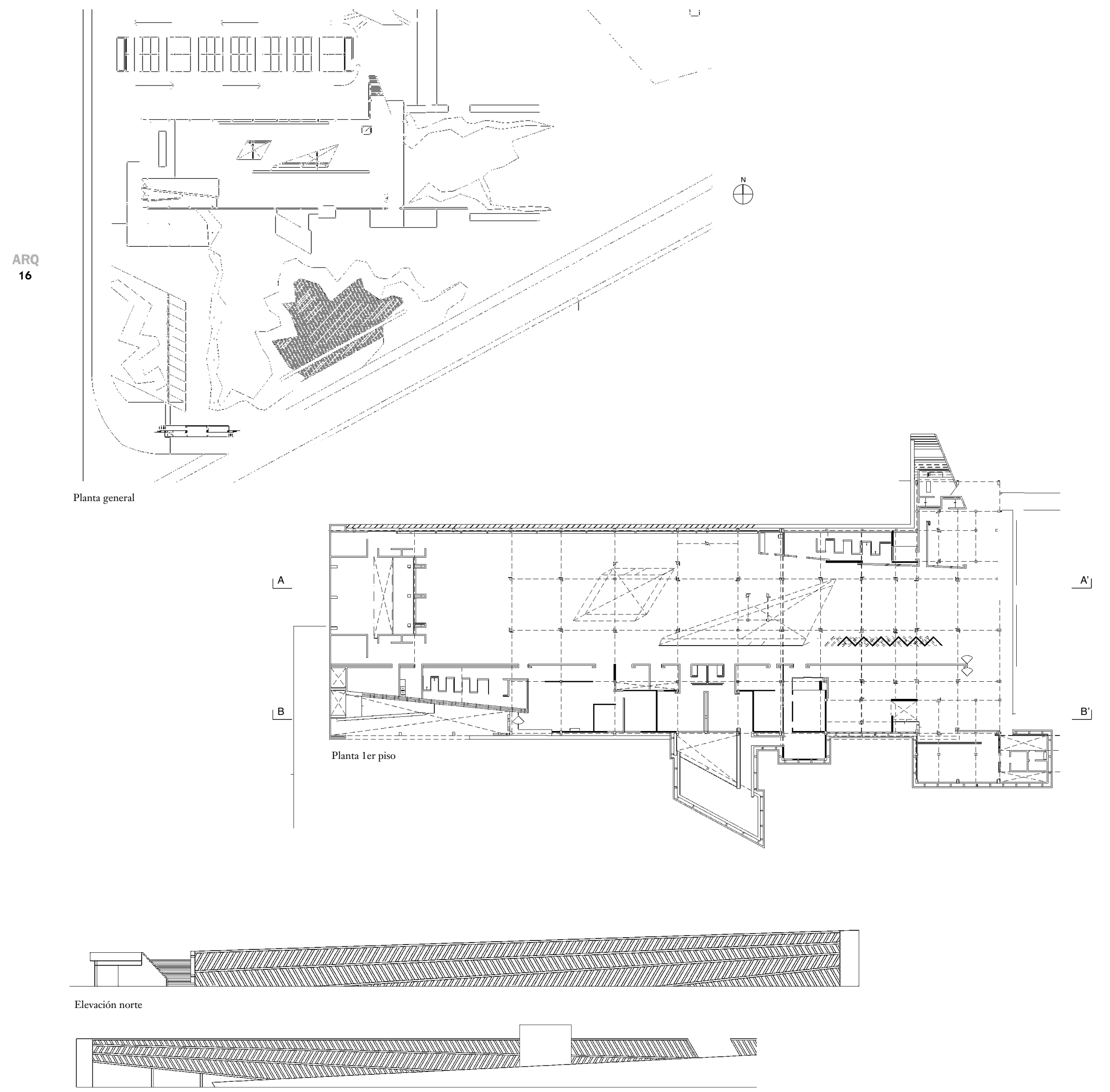

Elevación sur
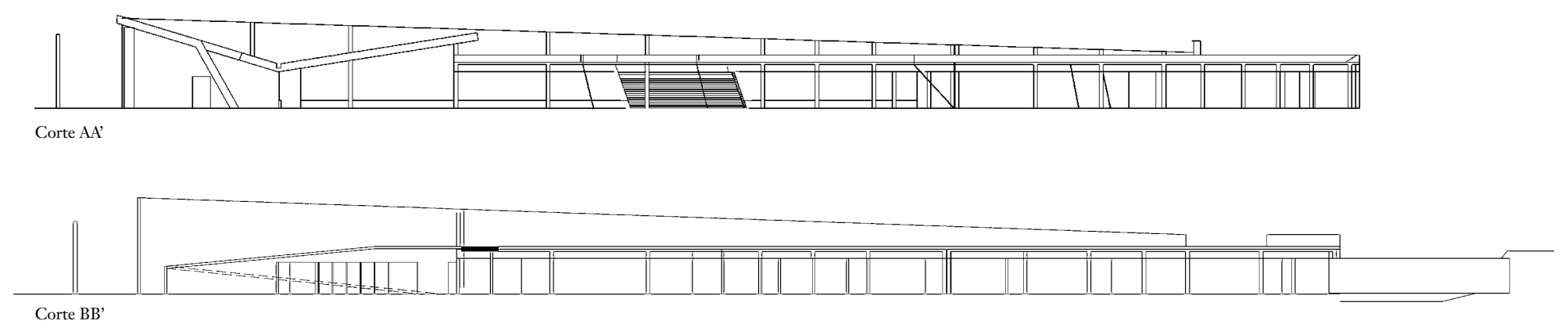


\begin{tabular}{|c|c|c|c|}
\hline $\begin{array}{l}4 \text { y } 6 \text { Espacio interior oficinas } \\
5 \text { Patios de luz interiores } \\
\text { del espacio de oficinas }\end{array}$ & 7 & $\begin{array}{l}\text { Estructura preexistente } \\
\text { con techo propuesto } \\
\text { Presentación de lainas }\end{array}$ & $\begin{array}{l}9 \text { Prefabricación horizontal } \\
\text { de lainas para el quebrasol } \\
10 \text { Acceso al edificio }\end{array}$ \\
\hline
\end{tabular}
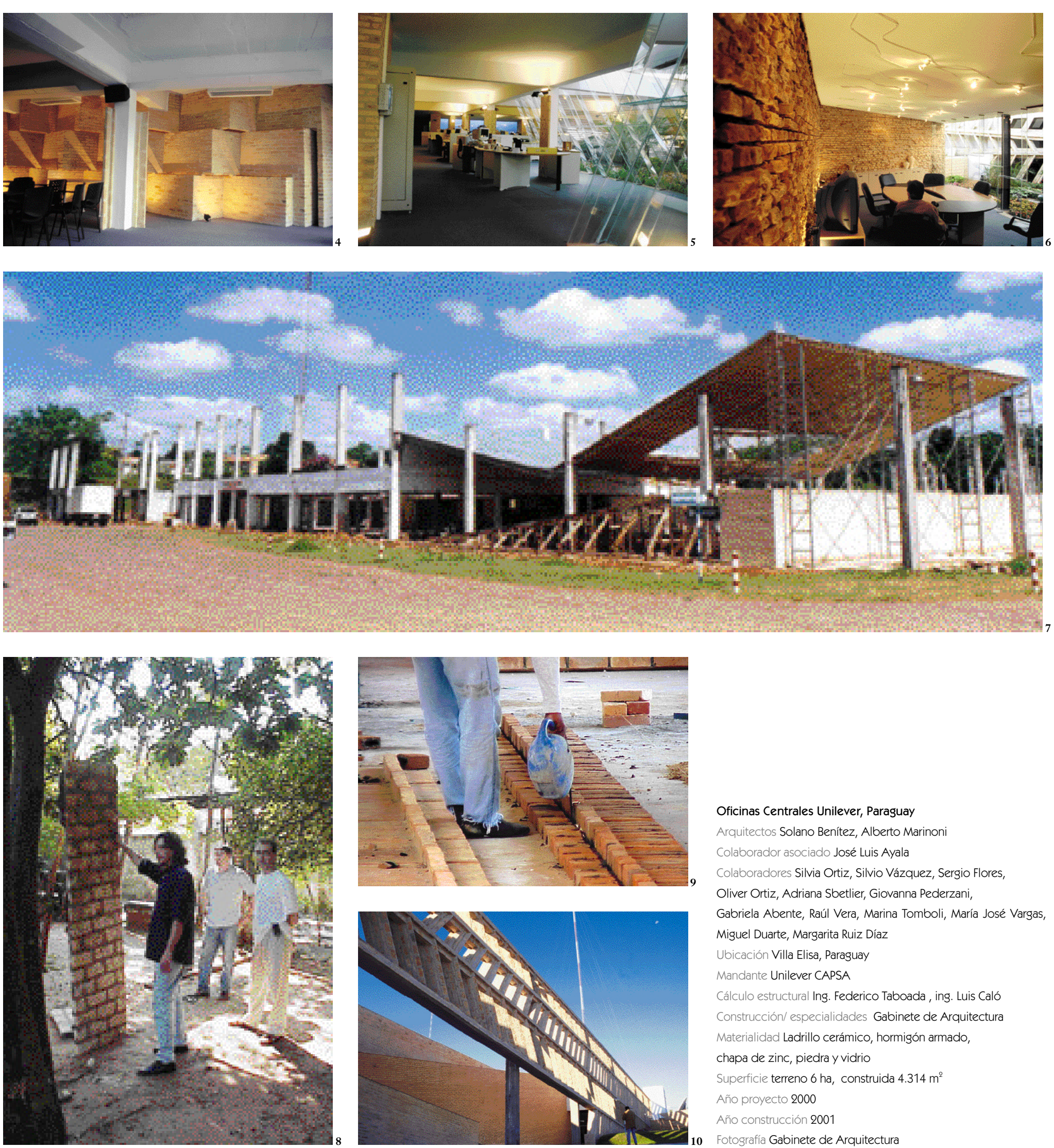

Oficinas Centrales Unilever, Paraguay

Arquitectos Solano Benítez, Alberto Marinoni

Colaborador asociado José Luis Ayala

Colaboradores Silvia Ortiz, Silvio Vázquez, Sergio Flores,

Oliver Ortiz, Adriana Sbetlier, Giovanna Pederzani,

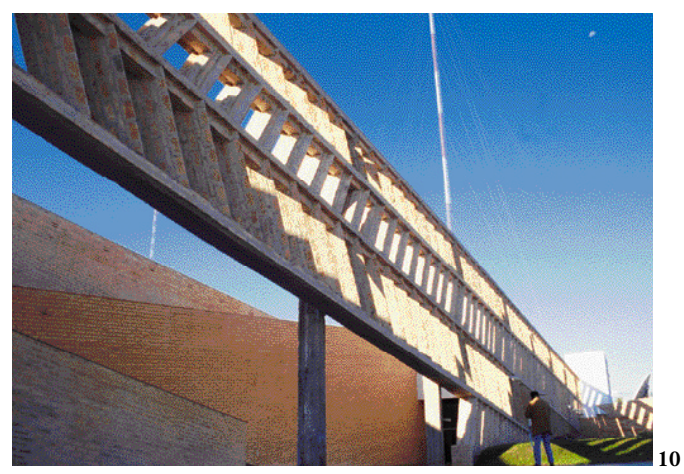

Gabriela Abente, Raúl Vera, Marina Tomboli, María José Vargas,

Miguel Duarte, Margarita Ruiz Díaz

Ubicación Villa Elisa, Paraguay

Mandante Unilever CAPSA

Cálculo estructural Ing. Federico Taboada, ing. Luis Caló Construcción/ especialidades Gabinete de Arquitectura Materialidad Ladrillo cerámico, hormigón armado,

chapa de zinc, piedra y vidrio

Superficie terreno 6 ha, construida $4.314 \mathrm{~m}^{2}$

Año provecto 2000

Año construcción 2001

Fotografía Gabinete de Arquitectura 

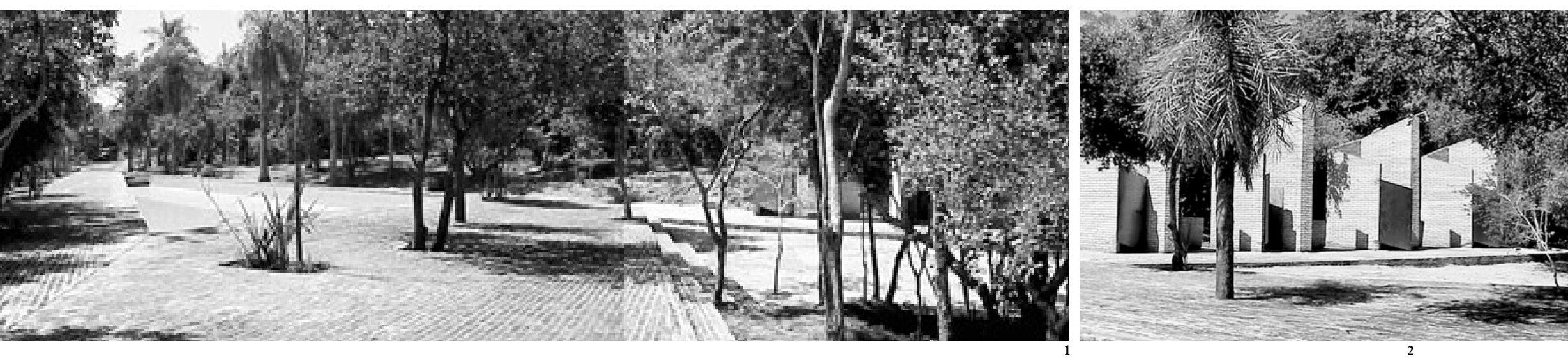

\section{Complejo Vacacional, Ytú, Parasuay}

Tras la revolución de febrero de 1989, se otorga a trabajadores de los monopolios estatales derecho de integrar sociedades sindicales.

Resultamos ganadores de un concurso organizado por este sindicato, que integra en plantilla de funcionarios desde encargados de aseo hasta las complejas gerencias técnicas, y que operan en plantas de escenarios muy distintos, asentadas en capital y hasta en periféricas y diminutas comunidades rurales.

El sitio del proyecto, Ytú, se encuentra a $50 \mathrm{~km}$ de la ciudad de Asunción; serranías, montes y un arroyo integran las 10 ha del conjunto, sobrevivientes de los parcelamientos de lotes de especulación inmobiliaria en los que se hallan inscritas. El lugar ya estaba contado, pervive en recuerdos futuros, la propuesta es sólo una estrategia de intervención. Un proyecto extensible y transformable, hecho de marcas fundacionales en la necesidad de nombrar el lugar. El proyecto, comprometido con una profunda austeridad, habrá de rehacerse repitiendo el gesto en cada parte.
La construcción es la del límite, lo más cercana a refugios de distintas escalas, que se entretejen con árboles, que copian la silueta de los cerros, que inauguran topografías que se clavan o emergen del suelo, donde se encuentran con la intensidad del sol y la generosidad de las sombras, la lluvia, los vientos, sus sonidos y olores. Sólo el lugar determina el adentro y el afuera.

Pretendemos el desarrollo de una modernidad sensible, que nos permita poner en tren de superación el aprovechamiento de nuestros recursos y potencialidades, de materiales y procedimientos. La cestería nos da la clave de esfuerzos y contraesfuerzos a los que sometemos la madera de baja densidad para evitar su libre deformación a la intemperie. La paja utilizada como aislante térmico sobre los techos y la tierra encauzando y conteniendo los raudales de la sierra, son algunos recursos constructivos explorados por esta propuesta.

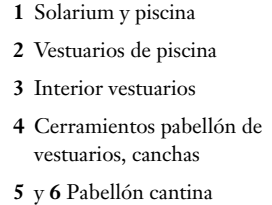

Complejo Vacacional, Ytú, Parasuay

Arquitectos Solano Benítez, Alberto Marinoni Colaborador asociado José Luis Ayala Colaboradores Silvio Vázquez, Silvia Ortiz, Giovanna Pederzani, Carlos Díaz Meyer, Sergio Faneso, Rosa Sarubbi, Mirna Cruz, Alejandra Sánchez,

Claudia Fleitas, Jazmín Chilavert, Gonzalo Meza Ubicación Ytú, Caacupé, Parasuay

Mandante Sindicato de Trabajadores de la Asociación Nacional de Electricidad (SITRANDE)

Cálculo estructural Ing. Gilberto Calderoli

Construcción/ especialidades Gabinete de Arquitectura Materialidad ladrillo cerámico y madera.

Superficie terreno 10 ha, construida $5.868 \mathrm{~m}^{2}$ Año proyecto 1997

Año construcción 1998

Fotografía Gabinete de Arquitectura

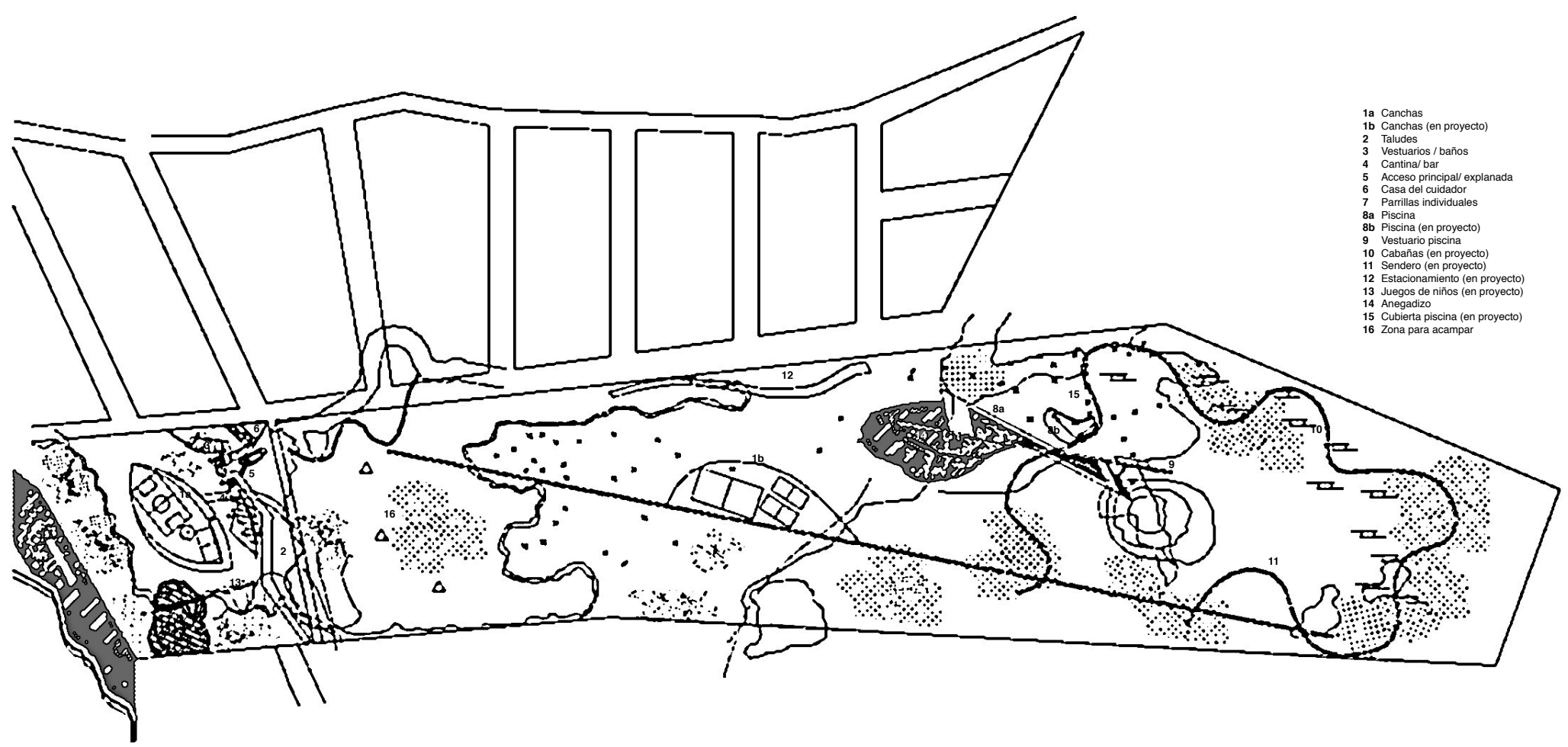

Plano emplazamiento 

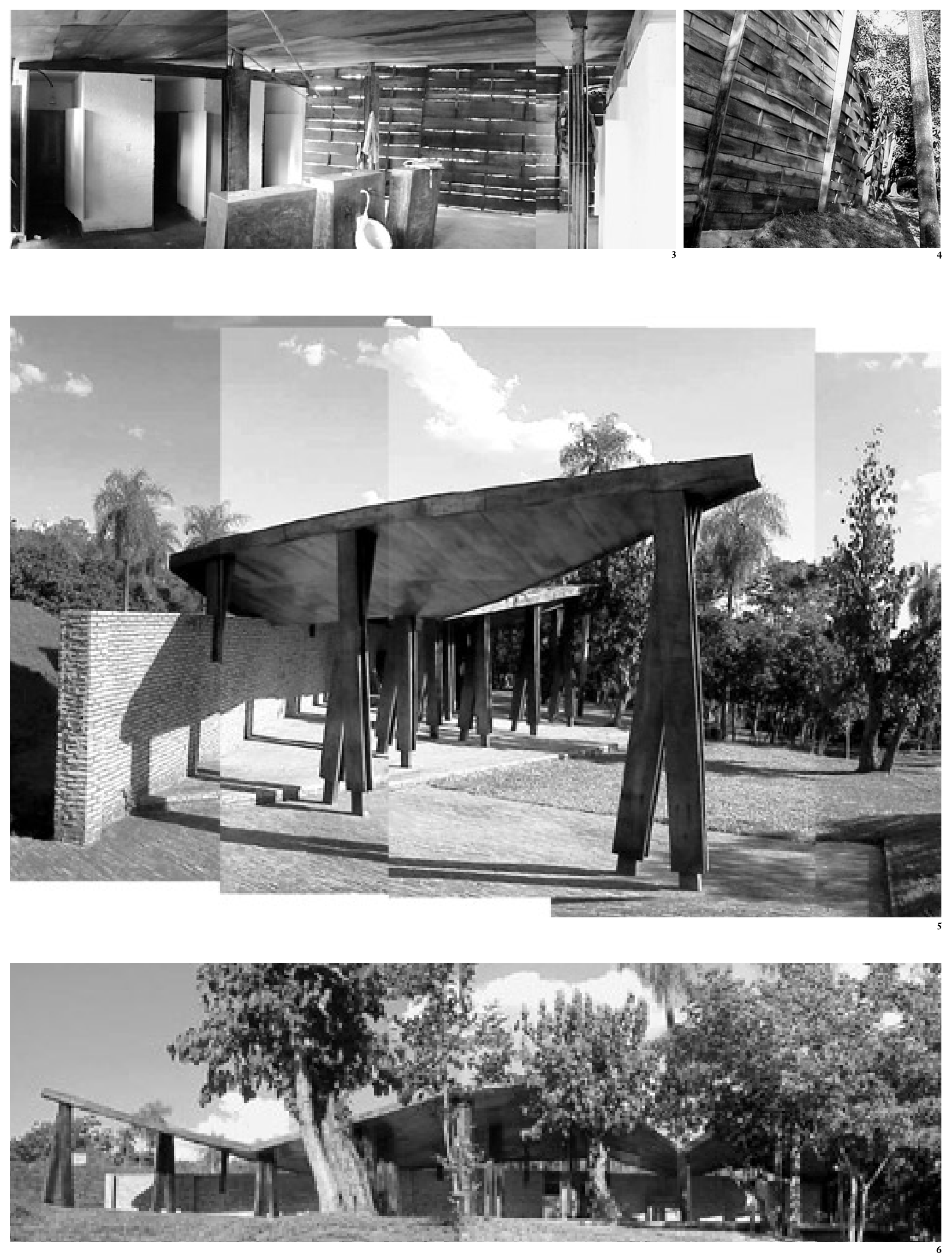
ARQ Tumba en Piribebuy
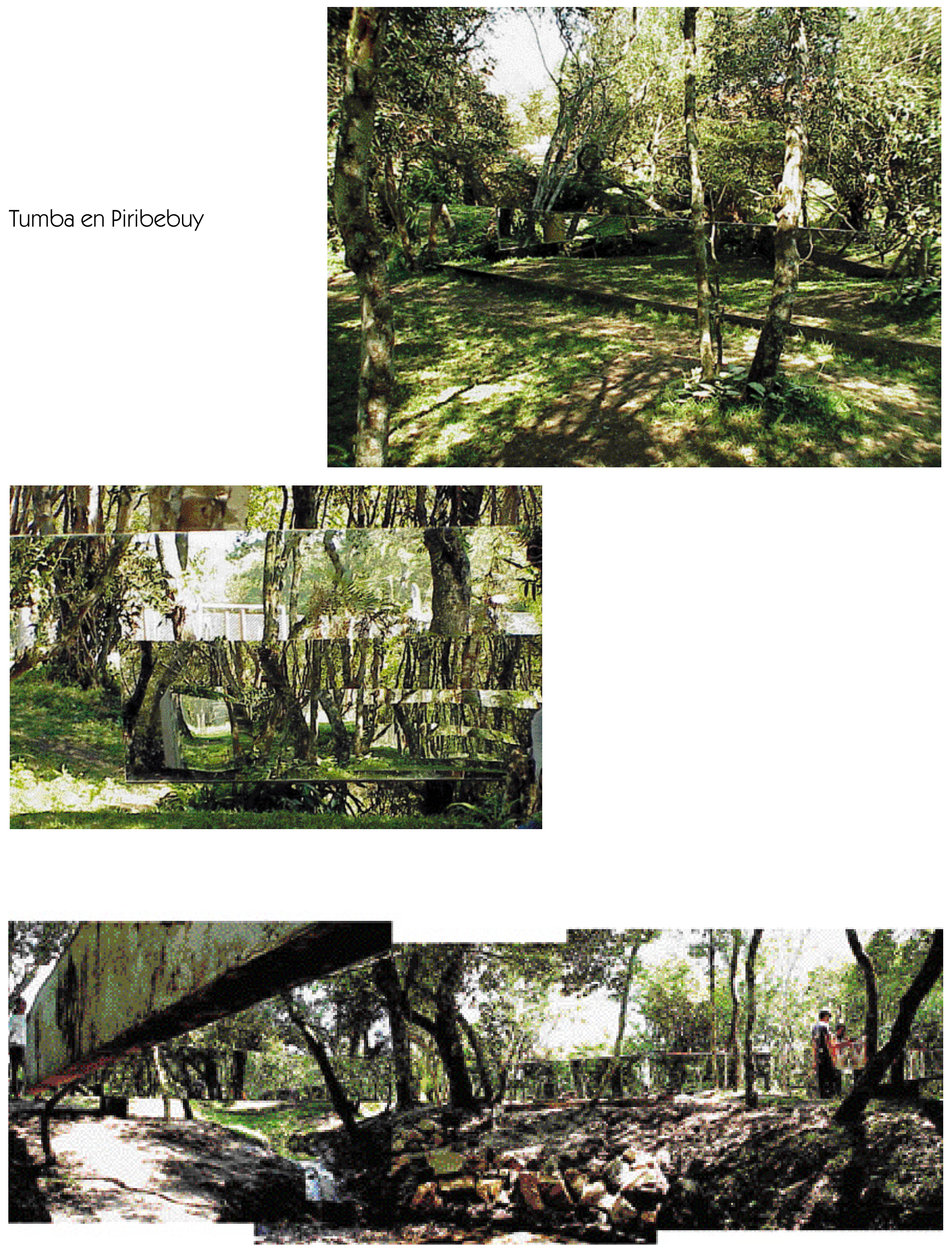


\section{Fragmento de una carta}

“...estoy construyendo un proyecto que me demoré diez años en hacerlo.

Imaginá un cuadrado de $9 \mathrm{~m}$ de lado en un paisaje muy particular, dos de los lados están bordeados de manera irregular por un pequeño arroyo de aguas cristalinas de $60 \mathrm{~cm}$ de ancho promedio, con pequeñas caídas de agua de $30 \mathrm{~cm}$; y atravesando como en diagonal el cuadrado, transcurre otro curso menor que corre configurando una pequeña isla que desaparece a pocos metros, donde reconfluyen las aguas.

Este cuadrado está conformado por cuatro vigas de hormigón sostenidas cada una por un solo pilar. Te imaginarás, debido a la humedad de los cauces del arroyo, que este lugar está particularmente vegetado, y que las vigas se entrecruzan con la densidad arbórea y los helechos de gran porte, sin molestar a ninguna especie. El lugar así queda nombrado desde afuera con esta entrelazante estructura de hormigón.

En la cara externa de cada una de las vigas, en el encofrado, se introdujeron hojas de amambay -un helecho muy característico de estos arroyos-, que estampa de esta forma su huella en el hormigón y fue ejecutado con la ayuda del maestro "Solanito", mi apasionado hijo mayor.

La cara interna de las vigas está recubierta de espejos, de forma tal que el espacio nombrado desde fuera desaparezca desde dentro.

En el interior del cuadrado, esquivando las raíces, a la sombra de los árboles y poblado por el sonido del agua de los arroyos, hay una fosa, también de hormigón armado; que será de ahora en adelante, la tumba de mi padre.

Este proyecto lo abordé sistemática y periódicamente a lo largo de estos diez años que ya transcurrieron desde su muerte; y lo abandoné con la misma constancia con que surgía la necesidad de elaborarlo, cumpliendo un pedido suyo de ser enterrado en nuestra casa quinta de la localidad de Piribebuy, a $84 \mathrm{~km}$ de Asunción, en el departamento de la cordillera, en el lugar por él bautizado "Los Pilinchos", sucursal del cielo. Esta circunstancia de abordar el tema de la muerte, y en particular la de alguien tan amado, a lo largo de este tiempo me hizo atravesar todos los estados de la melancolía imaginables -único justificativo a mi inoperancia como arquitecto.

$\mathrm{El}$ ingreso atravesando la señal de las vigas, por los cuatro espacios interrumpidos del perímetro, hace desaparecer el lugar o densifica el aire con una fuerza centrípeta muy especial, donde todo lo presente queda integrado, esperando el momento en que se tome asiento junto al lugar de la tumba, momento en el cual toda presencia es asimilada por los espejos, que en su infinita repetición del espacio, lo transforma ahora sí en un integrador centrífugo.

Recordá que la altura de las vigas es la normal de una baranda, de aproximadamente $1.10 \mathrm{~m}$ de alto, entonces al estar parado en ese espacio, la vista normal recorre más metros que la superficie de $81 \mathrm{~m} 2$ inscrita y resonante.

Sé que es recurrente asociar la idea de los espejos al enamoramiento egoísta por excelencia, el narcisismo; pero hay una cosa que siempre me fascinó de los reflejos, la internalidad de "uno" y la externalidad de lo "otro" claudica en esta superficie, yo habito dentro mío, y yo soy el límite que me separa de lo otro. La excepción que abrazo con desesperación es el espejo.

En el espejo yo estoy “allî”, en frente, fuera de mí mismo, habitando una otra dimensión que me iguala a todo lo demás, o que me permite habitar en un otro mundo que no sea mi interior, en un plano de igualdad y simultaneidad; tal vez en el espejo tengamos la máquina capaz de permitirnos el habitar de otra forma con nuestros seres... los amados ausentes, porque la obscenidad de la muerte les arrancó de nuestro lado... los que son el amor imposible, porque nunca encontramos $\mathrm{n}$ el espacio ni el tiempo que les permita existir..

Esta pequeña obra creo que tiene un particular carácter exorcisador para mí, y espero de ella un efecto por demás positivo en el gerenciamiento relacional con todos mis fantasmas.

Me gustaría que sepas que "la invención de Morel" sigue dando frutos -aunque muy influenciado además por mis queridos hermanos brasileños, también estoy tentado a explicar para ellos esta obra de la siguiente manera... 4 vigas... 4 pilares... 4 espejos... y una fosa- aunque la poesía concreta sea para mí una refrescante novedad.
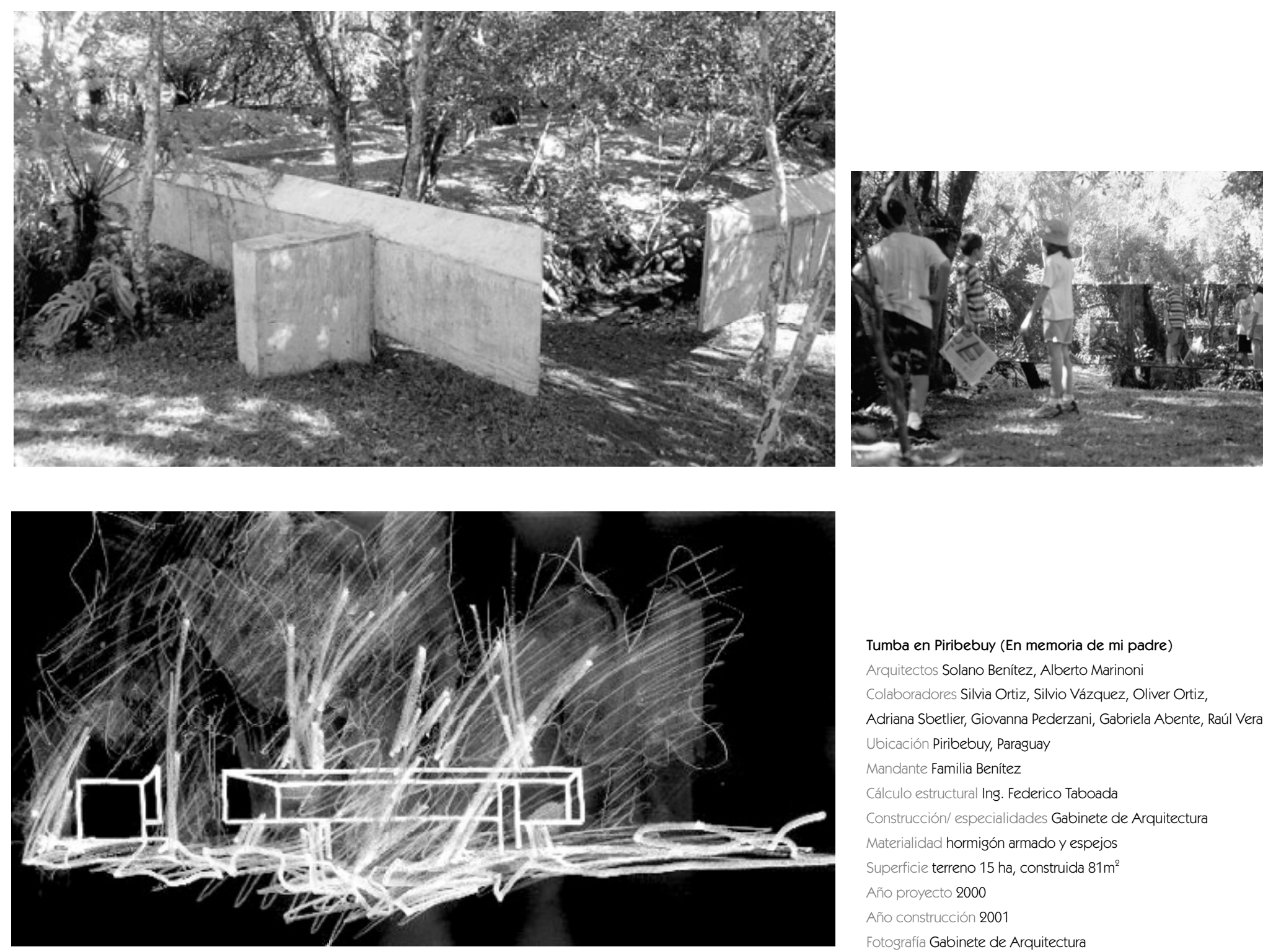

Tumba en Piribebuy (En memoria de mi padre)

Arquitectos Solano Benítez, Alberto Marinoni

Colaboradores Silvia Ortiz, Silvio Vázquez, Oliver Ortiz,

Adriana Sbetlier, Giovanna Pederzani, Gabriela Abente, Raúl Vera

Ubicación Piribebuy, Parasuay

Mandante Familia Benítez

Cálculo estructural Ing. Federico Taboada

Construcción/ especialidades Gabinete de Arquitectura

Materialidad hormigón armado y espejos

Superficie terreno 15 ha, construida $81 \mathrm{~m}^{2}$

Año proyecto 2000

Año construcción 2001

Fotografía Gabinete de Arquitectura 